\title{
In-situ Transesterification of Jatropha curcas L. Seeds for Biodiesel Production using Supercritical Methanol
}

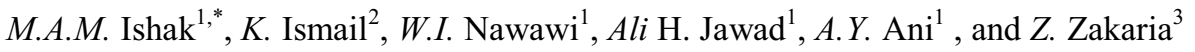 \\ ${ }^{1}$ Faculty of Applied Sciences, Universiti Teknologi MARA, Perlis Branch, 02600 Arau, Perlis, \\ Malaysia \\ ${ }^{2}$ Faculty of Applied Sciences, Universiti Teknologi MARA, 40450 Shah Alam, Selangor, Malaysia \\ ${ }^{3}$ Faculty of Engineering Technology, Universiti Malaysia Perlis, 02100 Padang Besar, Perlis, \\ Malaysia
}

\begin{abstract}
In-situ supercritical methanol transesterification for production of biodiesel from Jatropha curcas L. (JCL) seeds was successfully being carried out via batch-wise reactor system, under varying temperatures of $180-300{ }^{\circ} \mathrm{C}$, pressures of $6-18 \mathrm{MPa}$, reaction time of $5-35 \mathrm{~min}$ and seeds-to-methanol ratio of 1:15-1:45 (w/v). In this study, the extracted oil obtained showed the presence of FAME referring as biodiesel, indicating that transesterification reaction had occurred during the extraction process. The results showed that the biodiesel yield was obtained at optimum conditions of $280^{\circ} \mathrm{C}, 12 \mathrm{MPa}, 30 \mathrm{~min}$ and $1: 40(\mathrm{w} / \mathrm{v})$ were $97.9 \%$.
\end{abstract}

\section{Introduction}

Vegetable oil methyl esters, commonly referred to as biodiesel are prominent candidates as alternative to diesel fuels [1]. Biodiesel is technically competitive with or offers technical advantages compared to conventional petroleum diesel fuel. The vegetable oils, as alternative engine fuels, are all extremely viscous with viscosities ranging from 10 to 20 times greater than that of petroleum diesel fuel [2]. Fortunately, inedible vegetable oils, mostly produced by seed-bearing trees and shrubs can provide as alternative for biodiesel sources. Among the various renewable energy choices, seed oil crops especially the Jatropha curcas $L$. has a high potential to meet with the increasing requirements of petroleum and its products. With no competing food uses, this characteristic turns attention to Jatropha curcas, which grown in tropical and subtropical climates across the developing world [3]. It is significant to point out that, the inedible vegetable oil of Jatropha curcas has the requisite potential of providing a promising and commercially viable alternative to diesel oil since it has desirable physicochemical and performance characteristics comparable to diesel.

Recently, oil contents, fatty acid methyl esters (FAME) compositions and energy values of Jatropha species were investigated [1]. The conventional method of extracting the oils

*Corresponding author: azlanishak@perlis.uitm.edu.my 
from Jatropha seeds is through mechanical screwed pressing technique. However, much of the un-extractable oil still remains in the kernel; hence better ways of extracting the oils are needed. Among the extraction techniques reported in the literature include the use of ultrasound-assisted system [4], enzymes extraction [5] and the use of catalytic materials [6]. Some of these extraction methods, however, required a longer extraction time and multiple steps to achieve. However, the used of in-situ supercritical methanol extraction on Jatropha seeds has not been reported thus far. Supercritical fluid extraction using polar solvent such as methanol as extraction solvent is highly potential extraction technique to be used whereby high yield of oil can be achieved within a shorter time. Further, at supercritical state, the solvent solubility increased dramatically, and the extracted oil is relatively low in impurities. The objectives of this study is to determine the effect of parameters i.e. temperatures, pressures, reaction times and ratios on the percent of biodiesel yields from the in-situ supercritical methanol transesterification.

\section{Materials and methods}

\subsection{Materials}

Matured JCL fruits were obtained from Plantation Unit of Universiti Teknologi MARA Perlis, Malaysia. The fruits were cleaned and de-hulled to obtain the seeds. The seeds were then dried in an oven at $105^{\circ} \mathrm{C}$ for $30 \mathrm{~min}$ in order to remove surface moisture and ground to particle size of less than $1 \mathrm{~mm}$ using grinder. All of the chemicals used were of analytical reagent grade.

\subsection{In-situ supercritical methanol transesterification}

A batch type reactor at supercritical methanol was used for in-situ conversion of JCL seeds and into biodiesel. A schematic diagram of the system employed is shown in Fig. 1. A 1 liter stainless steel reactor (PAAR Model 4571) was charged with the seeds to methanol ratio $(\mathrm{w} / \mathrm{v})$ of 1:40. The reaction vessel was heated with a heater to the desired reaction temperatures $\left(180-300{ }^{\circ} \mathrm{C}\right)$, pressures $(6-18 \mathrm{MPa})$, reaction times $(5-35 \mathrm{~min})$ and seeds-to-methanol ratios $(1: 15-1: 45 \mathrm{w} / \mathrm{v})$. After each reaction the vessel was removed from the heater and placed into a cold water bath to quench the reaction. The reaction products were discharged from the reactor and were evaporated to remove the methanol. The products were allowed to settle and separated into two phases. The top phase consists of the methyl ester (biodiesel) and the lower phase consists of glycerol with a minor components.

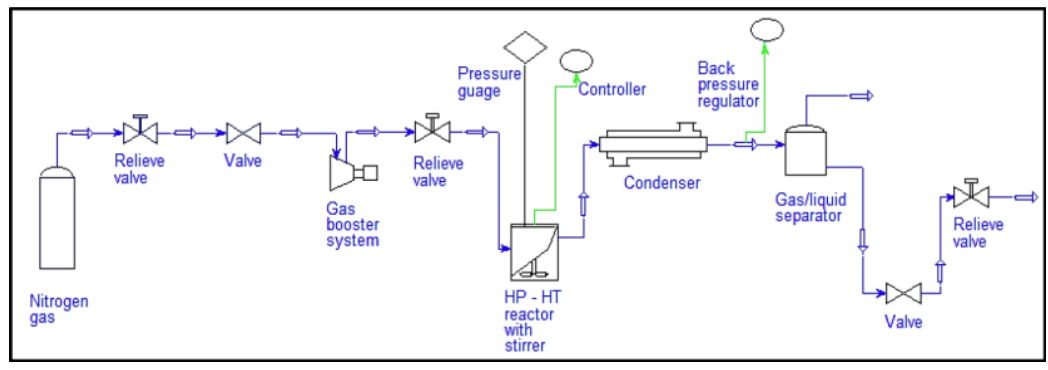

Fig. 1. Experimental set-up of the batch-wise reactor system used in the study. 


\section{Results and discussion}

\subsection{Effect of temperature}

The effect of temperature on percent of biodiesel yield from JCL seeds were investigated. These experiments were carried out at $12 \mathrm{MPa}$ of pressure, 1:40 of seeds-to-methanol ratio, $30 \mathrm{~min}$ of reaction time, $450 \mathrm{rpm}$ of stirring speed and at varying temperatures of 180, 200, 240, 280 and $300{ }^{\circ} \mathrm{C}$. The results of in-situ supercritical methanol transesterification on percent of biodiesel yield from JCL seeds at various temperatures are shown in Fig. 2. From Fig. 2, the results indicate that the percent of biodiesel yield obtained at temperatures of 180 to $300{ }^{\circ} \mathrm{C}$ were in the range of $51.2-97.9 \%$. At $180{ }^{\circ} \mathrm{C}$, which is the lowest temperature of investigation, low yield of biodiesel $(51.2 \%)$ were obtained. This observation might be due to the subcritical state of methanol or the instability of the supercritical state of methanol [7-9]. Apparently, by increasing the reaction temperature from 200 to $280{ }^{\circ} \mathrm{C}$, the conversion increases significantly with biodiesel yield increased from $76.0-97.9 \%$. The higher conversions observed in the supercritical state can be attributed to the formation of a single phase between alcohol and oil [8]. Under supercritical conditions, the solubility parameter of alcohol reduces and was close to the solubility parameter of oil [10]. At the $300{ }^{\circ} \mathrm{C}$ of temperature, the percent of biodiesel $(90.9 \%)$ yields were slightly decreased. This observation was due to the decomposition of polyunsaturated methyl esters and unreacted triglycerides in postcritical methanol at severe high temperature [11]. As a result, the effect of temperature from in-situ supercritical methanol transesterification was optimized at $280{ }^{\circ} \mathrm{C}$ with biodiesel yield at $97.9 \%$.

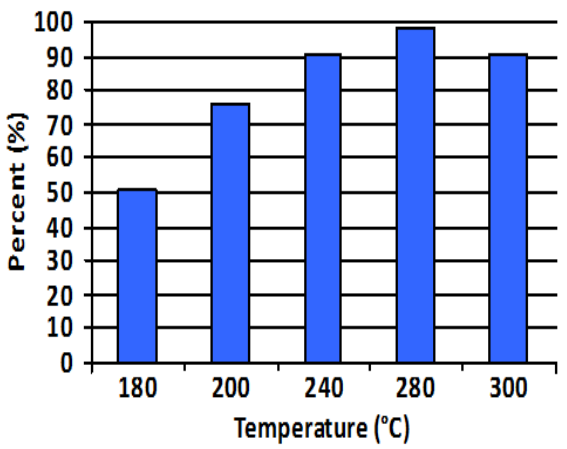

Fig. 2. Effect of temperatures on percent of biodiesel yield.

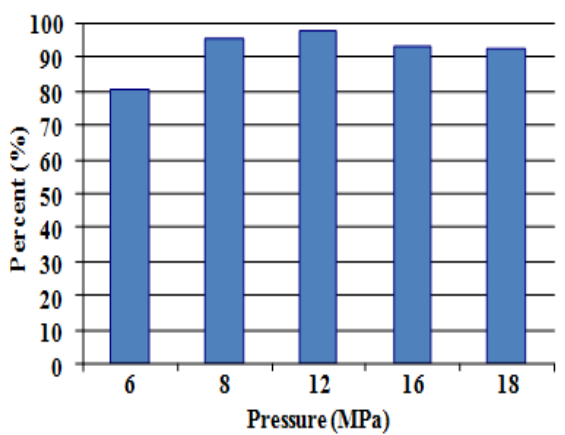

Fig. 3. Effect of pressure on percent of biodiesel yield 


\subsection{Effect of pressure}

The results of in-situ supercritical methanol extraction and transesterification in-situ on percent of extraction (seed basis) and FAMEs yield from JCL seeds at various pressures are shown in Fig. 3. The temperature was fixed at $280{ }^{\circ} \mathrm{C}$ based on the maximized yield conditions from the previous experiment. Meanwhile the seeds-to-methanol and reaction time was fixed at 1:40 w/v and $30 \mathrm{~min}$, respectively with stirring speed of $450 \mathrm{rpm}$. From Fig. 3, the results indicated that the percent of biodiesel yield obtained at temperatures of $280{ }^{\circ} \mathrm{C}$ and pressures of 6-18 $\mathrm{MPa}$ was in the range $80.6-97.9 \%$, with maximum yields at $12 \mathrm{MPa}$. At the lowest pressure of $6 \mathrm{MPa}$, the biodiesel yield are only $80.6 \%$, but increases to $97.9 \%$, when the pressure are increased to $12 \mathrm{MPa}$. The high biodiesel yield achieved at $12 \mathrm{MPa}$, which is slightly above the critical pressure of methanol (8.09 MPa), might be due to the increase in solvent power of methanol with increasing pressure. At highest pressure (18 MPa), the biodiesel yield decreases slightly to $92.5 \%$. After the pressure increased to a specific level, the increase of pressure does not cause an obvious improvement in the FAME yield [12]. This phenomenon might be due to the maximum solubility and/or hydrogen donor ability of the solvent that has been achieved regardless of high pressure employed. Thus, a $12 \mathrm{MPa}$ of pressure was chosen in order to maximize the biodiesel yield up to $97.9 \%$.

\subsection{Effect of reaction time}

Fig. 4 shows the effect of reaction time on percent biodiesel yield from JCL seeds using insitu supercritical methanol transesterification. The reaction conditions were fixed based on maximum yields at optimized conditions discussed previously, i.e. $280{ }^{\circ} \mathrm{C}$ of temperature, 12.7 $\mathrm{MPa}$ of pressure and 1:40 seeds-to-methanol ratios at different reaction times. From Fig. 4 , the results indicated that the percent of biodiesel yield obtained at reaction time of 5 - $35 \mathrm{~min}$ was in the range of $88.4-97.9 \%$, with maximum yields at $30 \mathrm{~min}$. From the results, it can be seen that the percent of biodiesel yield were only $88.4 \%$, at $5 \mathrm{~min}$ of reaction time. According to Saka and Kusdiana [13], in the common method, the reaction is initially slow because of the two-phase nature of the methanol/oil system, and slows even further because of the polarity problem even with the help of an acid or an alkali catalyst. It can be seen that the conversion was increased in the reaction time ranges between 5 and 30 min with the percent of biodiesel yield showed a slight increase in the range of $88.4-$ $97.9 \%$. Thus, the percent of biodiesel yield showed an increased with increasing reaction time. The results indicated that an extension of the reaction time from 30 to $35 \mathrm{~min}$ had leads to a reduction in the biodiesel yield $(93.1 \%)$. This is because longer reaction time enhanced the hydrolysis of esters (reverse reaction of transesterification), resulted in loss of esters as well as causing more fatty acids to form soap [14]. Hence, for this process, there is no reason to prolong the reaction time beyond $30 \mathrm{~min}$. Thus, the reaction time of $30 \mathrm{~min}$ can be considered as the economic reaction time by considering the percent of biodiesel yield being achieved. 


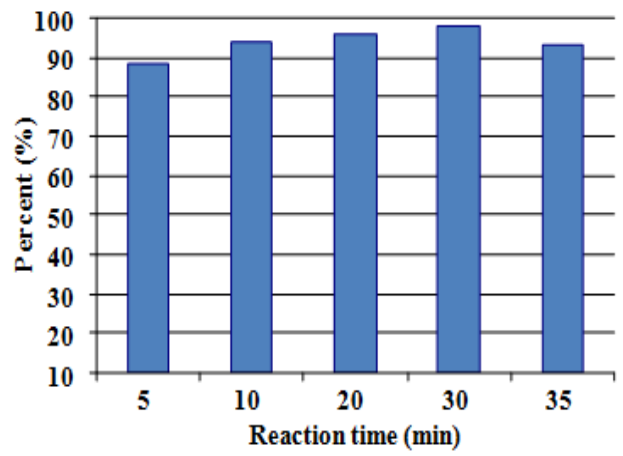

Fig. 4. Effect of reaction time on percent of biodiesel yield.

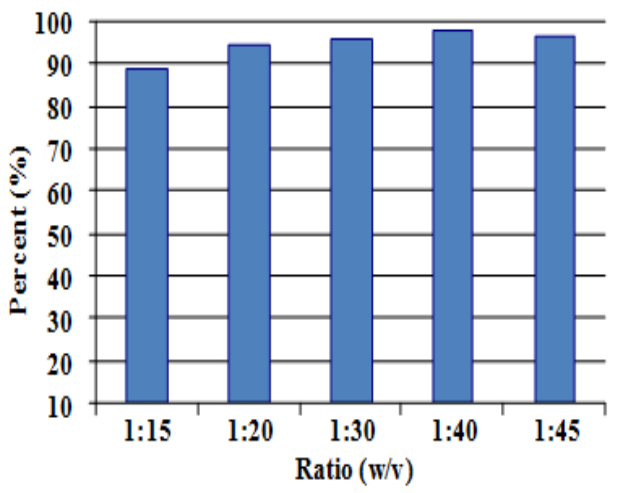

Fig. 5. Effect of ratio on percent of biodiesel yield.

\subsection{Effect of seeds-to-methanol ratio}

Fig. 5 shows the effect of seeds-to-methanol ratio on percent of biodiesel yield from JCL seeds using in-situ supercritical methanol transesterification. The reaction conditions were fixed based on maximized yields at optimized conditions discussed previously, i.e. $280{ }^{\circ} \mathrm{C}$ of temperature and $12.7 \mathrm{MPa}$ and $30 \mathrm{~min}$ of reaction time at different ratios. The results indicated that the percent of biodiesel yield obtained at temperatures of $280{ }^{\circ} \mathrm{C}$, pressures of 12.7 $\mathrm{MPa}$, reaction time of $30 \mathrm{~min}$ and at various seeds-to-methanol ratio $(1: 15-1: 45 \mathrm{w} / \mathrm{v})$ was in the range of $89.0-97.9 \%$, with maximum yields at $1: 40 \mathrm{w} / \mathrm{v}$. At the lowest seedsto-methanol ratio of $1: 15$, the percent of biodiesel yield were relatively low $(89.0 \%)$ and increased with increasing seeds-to-methanol ratio. In this reaction, an excess of methanol was used in order to shift the equilibrium in the direction of the products [15]. It can be seen that an increment in seed-to-methanol ratio can enhance biodiesel yield due to higher contact area between methanol and triglycerides. However, when the ratio is beyond 40 , the yield of biodiesel begins to decrease substantially. This might be due to the restriction of the reaction equilibrium and difficulties in separating excessive methanol from methyl esters and glycerol, which subsequently lowered the yield of biodiesel [11]. Maximum percent of biodiesel yield were obtained at a 1:40 of seeds-to-methanol ratio.

\section{Conclusions}

Based on the findings, it can be concluded that temperature is an important property in this in-situ process. As the temperature increased, the extraction and FAMEs yields also 
increased. The loss was caused by thermal decomposition, dehydrogenation and other side reactions. For the effect of pressure, the extraction and FAMEs yield increased with increasing pressure. For the effect of reaction time, it can be seen that the conversion was increased in the reaction time ranges between 5 and $30 \mathrm{~min}$, and thereafter reduced as a representative of the equilibrium conversion. The excess reaction time did not promote the conversion but favors the reverse reaction of transesterification which resulted in a reduction in the ester yield. For the effect of seeds-to-methanol ratio, it can be seen that an increment in seed-to-methanol ratio can enhance biodiesel yield due to higher contact area between methanol and triglycerides. However, when the ratio is beyond 40, the yield of biodiesel begins to decrease substantially.

This research work was funded by the Ministry of Education, Malaysia under the FRGS grant scheme. The authors also thank the management of Universiti Teknologi MARA for supporting the research work.

\section{References}

1. W.N.M.W. Ghazali, R. Mamat, H.H. Masjuki, G. Najafi, Renew. Sustainable Energy Rev., 51, 585 (2015)

2. A. Demirbas, Prog. Energy Combust. Sci., 31, 466 (2005)

3. H.J. Berchmans, S. Hirata, Bioresour. Technol., 99, 1716 (2008)

4. E. Fayyazi, B. Ghobadian, G. Najafi, B. Hosseinzadeh, R. Mamat and J. Hosseinzadeh, Ultrason. Sonochem., 26, 312 (2015)

5. E.C.G. Aguieiras, E.D.C. Oliveira, D.M.G. Freire, Fuel, 159, 52 (2015)

6. M.R. Avhad, J.M. Marchetti, Renew. Sustainable Energy Rev., 50, 696 (2015)

7. W. Cao, H. Han, J. Zhang, Fuel, 84, 347 (2005)

8. G. Madras, C. Kolluru, R. Kumar, Fuel, 83, 2029 (2004)

9. K. Bunyakiat, S. Makmee, R. Sawangkeaw, Ngamprasertsith, Energ. Fuel, 20, 812 (2006)

10. H. Han, W. Cao, J. Zhang, Process Biochem., 40, 3148 (2005)

11. K.T. Tan, K.T. Lee, A.R. Mohamed, Biomass Bioenergy, 33, 1096 (2009)

12. H. He, T. Wang, S. Zhu, Fuel, 86, 442 (2007)

13. S. Saka, D. Kusdiana, Fuel, 80, 225 (2001)

14. T. Eevera, K. Rajendran, S. Saradha, Renewable Energy, 34, 762 (2009)

15. A. Demirbas, Energy Conversion and Management, 48, 937 (2007) 